\title{
The newly formed Mite Specialist Group of the IUCN's Species Survival Commission and the conservation of global mite diversity
}

\author{
Sebahat K. OZMAN-SULLIVAN 1 (D), Gregory T. SULLIVAN ${ }^{2,3}$ (D) \\ ${ }^{1}$ Ondokuz Mayıs University, Faculty of Agriculture, Department of Plant Protection, 55139, Samsun, Turkey \\ ${ }^{2}$ The University of Queensland, School of Biological Sciences, St. Lucia, 4072, Brisbane, Australia \\ ${ }^{3}$ Corresponding author: g.sullivan1@uq.edu.au
}

Received: 18 July 2021

Accepted: 30 July 2021

Available online: 31 July 2021

ABSTRACT: The most serious environmental challenge facing humanity is the massive, widespread and continuing loss of biodiversity due to human activities. The commonly reported root causes of the decline and extinction of species are the degradation, destruction and fragmentation of habitat; pollution; pesticide use; invasive species; climate change; and over-exploitation; with co-extinction cascades accelerating the losses. The current alarming rate of loss of species across the biodiversity spectrum has ecological, economic, social, aesthetic, cultural and spiritual impacts that directly undermine the welfare of all humanity. This unprecedented crisis demands an urgent, science-based, comprehensive, coordinated, global response. Among the organizations responding to the multifaceted challenge of biodiversity loss is the International Union for Conservation of Nature (IUCN). Its enormous pool of integrated expertise, technical capacity and policy experience makes the IUCN the global authority on the status of nature and the suite of measures needed to protect it. The largest of the IUCN's six commissions is the Species Survival Commission, a science-based network of over 160 Specialist Groups, including 17 invertebrate groups; Red List Authorities; and Task Forces. Despite there being an estimated 500,000 - 1,500,000 mite species, and their ubiquity in global ecosystems and fundamental role in many ecological processes, mites have received minimal attention on the global conservation agenda. The role of the newly formed Mite Specialist Group, which gained official status in April 2021, is to redress that situation. The mission of the group, which currently includes 65 mite specialists, ecologists, botanists, environmentalists and conservation practitioners from 36 countries on five continents, is to contribute to a collaborative global effort to conserve mite diversity through research, education, advocacy, community engagement and specific conservation initiatives.

Keywords: Acari, biodiversity, co-extinction, endangered species, IUCN Red List.

\section{INTRODUCTION}

There is a strong consensus in the scientific community that the decline of insects, other arthropods and all other forms of biodiversity is a serious threat that must be urgently addressed (Harvey et al., 2020). Moreover, Pimm (2021) stated that the on-going massive loss of biodiversity is the most serious environmental challenge facing humanity. Furthermore, Ceballos et al. (2020) stressed the absolute urgency of coordinated, comprehensive worldwide action to save the remaining biodiversity and the ecosystems on which it depends from the current, human-induced, catastrophic global extinction event.

Pimm et al. (2014) asserted that the primary or overarching drivers of the extinction of species are continuing human population growth and the increasing total consumption of natural resources. Habitat destruction, degradation and fragmentation, pollution; pesticides; invasive species, climate change and over-exploitation drive the extinction process (Harvey et al., 2020; Wagner et al., 2021). These drivers individually and collectively contribute to an acceleration of the extinction process through co-extinction cascades (Strona and Bradshaw, 2018).

Terrestrial biodiversity is far from uniformly distributed across the planet. More specifically, a substantial propor- tion is concentrated in biodiversity hotspots, most of which are located in the tropics and subtropics (Myers, 1988). The astounding levels of biodiversity contained in the hotspots makes them absolutely vital conservation priorities, although by definition they have suffered considerable degradation (Myers, 1988; Myers et al., 2000; Mittermeier et al., 2005). Despite their importance, Hu et al. (2021) reported major, on-going degradation of the biodiversity hotspots that even extended to large areas 'protected' by legislation.

To qualify as a biodiversity hotspot a region must satisfy two criteria, namely (i) the presence of at least 1500 endemic vascular plant species and (ii) have $30 \%$ or less of its original natural vegetation remaining. The currently recognized 36 terrestrial biodiversity hotspot areas cover only $2.5 \%$ of the earth's land surface but more than $50 \%$ of all plant species and nearly $43 \%$ of all terrestrial vertebrate species are endemic to them (Conservation International, 2021). In 27 of the biodiversity hotspots, the correlations between plant, vertebrate and phytoseiid mite diversity and endemism, and also the degree of congruence between their respective endemism levels, suggested that the distribution pattern of the phytoseiids closely matched those of the plants and vertebrates (Tixier and Kreiter, 2009). 
Among the organizations responding to the challenge of biodiversity loss in terrestrial, freshwater and marine environments across the planet is the International Union for Conservation of Nature (IUCN), which is based in Gland, Switzerland. The IUCN is a membership union comprised of both government and civil society organizations that harnesses the collective experience, resources and networks of more than 1,400 member organisations, including states, government agencies, NGOs, indigenous groups and affiliates, as well as 18,000 voluntary expert members of its commissions. This enormous pool of integrated expertise, technical capacity and policy experience makes the IUCN the global authority on the status of nature and the measures needed to protect it (IUCN, 2021).

The IUCN has official observer status at the UN General Assembly, which explains its strong influence in the shaping of international conservation policy. It has also shaped the major international conservation conventions, such as the Convention on Biodiversity (CBD), the World Heritage Convention (WHC) and the Convention on International Trade in Endangered Species of Wild Fauna and Flora (CITES). Moreover, the IUCN is well known for its flagship knowledge products, such as the Red List of Threatened Species $^{\text {TM }}$ (RLTS), the World Database on Protected Areas (WDPA), the Database of Key Biodiversity Areas (KBAs) and the Red List of Ecosystems (RLEs). In addition, it has published numerous international conservation standards and guidelines, such as the global standard for the identification of KBAs, the guidelines for the reintroduction of species and other conservation translocations, and the guidelines for species conservation planning (A. Hochkirch, pers. comm., 2 July 2021).

The IUCN has six interrelated commissions to support its goals, the largest of which is the Species Survival Commission (SSC). The SSC is a science-based network with more than 9,000 volunteer experts working in more than 160 Specialist Groups, Red List Authorities and Task Forces. Some groups address conservation issues related to particular groups of plants, animals and fungi, while others pursue broader objectives such as the reintroduction of species into former habitats, climate change, health of wildlife and sustainable use and trade. Seventeen of the specialist groups and one stand-alone Red List Authority represent the terrestrial, freshwater and marine invertebrates (IUCN, 2021), which until recently did not include a group specifically devoted to the interests of mites (Arachnida: Acari).

\section{FORMATION OF THE MITE SPECIALIST GROUP}

Conservative estimates of the total number of mite species range between 500000 and 1500000 (Walter and Proctor, 2013; Stork 2018; Sullivan and Ozman-Sullivan, 2021). There are 528 extant families and 5,629 extant genera, and $\sim 63,000$ described species (J. Hallan, pers. comm., March 2020 in Sullivan and Ozman-Sullivan 2021). Sullivan and Ozman-Sullivan (2021) estimated that $\sim 15 \%$ of mite species likely became extinct by 2000 , and that extinctions are currently expected to increase by between $0.6 \%$ and $6.0 \%$ by 2060 . The same authors further stated that, based on the work of Fonseca (2009), it is highly likely that at least 150,000 mite species in hostspecific relationships with plants and insects in the biodiversity hotspots are committed to extinction but mites have been largely neglected in reports on the global biodiversity situation. The situation of mites (and other organisms) in the vast areas outside the hotspots is understood to generally reflect their precarious situation within the hotspots. In a specific case, Napierala et al. (2018) reported that of the uropodid mites collected over more than 50 years of sampling across Poland, more than $40 \%$ of the species pool were classified as either endangered or critically endangered, when modified IUCN criteria were applied. However, only 11 mite species have been assessed for the IUCN Red List of Threatened Species, including the listing of one extinct species (IUCN, 2021).

The SSC of the IUCN has recognized the need to incorporate the broad spectrum of invertebrate diversity more fully into its agenda and is actively pursuing that course. Within that context, shortly after the publication of the paper by Sullivan and Ozman-Sullivan (2021), the authors were contacted by Dr. Axel Hochkirch, Chair of the IUCN's SSC Invertebrate Conservation Committee and Dr. Sergio Henriques, Invertebrate Conservation Coordinator at the Global Center for Species Survival, Indianapolis Zoo, and co-chair of the SSC Spider and Scorpion Specialist Group, who proposed that they establish a Mite Specialist Group (MSG). Drs. Ozman-Sullivan and Sullivan agreed and so began the application process to the SSC which required the meeting of a number of criteria, including those summarized below. After receiving feedback from Drs. Henriques and Hochkirch on a number of drafts, the application was submitted to the SSC for assessment and the MSG was given official status on 23 April of 2021.

A summary of how the criteria for SSC Specialist Group accreditation were met:

1. What are the key conservation issues facing the taxon or group?

Sullivan and Ozman-Sullivan (2021) reported on the specific conservation issues related to mites, including that vast numbers of range and microhabitat restricted species, including host-specific species, are at greater risk of population decline and extinction due to habitat destruction and climate change. The information in the references cited in that paper and herein provides a comprehensive perspective on the nature and distribution of biodiversity, decline of populations and extinctions, and measures which can minimize the rate of loss and in some cases, reverse the declines.

2. Why is this taxonomic level and / or geographic scope considered to be the most appropriate level at which to address these conservation issues?

Mites, which constitute an estimated $20 \%$ of all arthropods (Stork, 2018), are an extremely large and highly diverse group that represents a substantial proportion of all the biodiversity that was being underrepresented in SSC activities and reports. Furthermore, the formation of a group advocating specifically for mites complements the 
activities being conducted on behalf of other arachnid and arthropod groups. It also fills a gap in addressing the global conservation of soil and its fauna, a crucial component of most terrestrial ecosystems, and therefore an important element of the development of the Red List of Ecosystems.

3. Is there a clear gap for the group to fill, and a valueadded benefit that the formation of the group would deliver, rather than duplicate efforts of existing Specialist Groups or IUCN partner institutions?

There was a demonstrable void in advocacy and action for the conservation of mites, and because there are many host and range restricted endemic species, countries supporting global Red List Assessment will benefit from the formation of the MSG. In addition, the formation of the MSG, because of the great diversity and ubiquity of mites in terrestrial, freshwater and marine ecosystems, will substantially increase the comprehensiveness, accuracy and credibility of reports on the overall status of biodiversity.

Henriques et al. (2020) stated that current reporting on biodiversity loss may not adequately represent trends across taxa and ecoregions but sampled assessments can accelerate biodiversity monitoring and complement current metrics. Also, Hochkirch et al. (2021) proposed an 8point strategy for the next decade to address the deficiency of data for neglected taxa. In addition, Harvey et al. (2020) formulated a 'roadmap' for insect conservation and recovery. All three of these approaches are directly applicable to mites, especially given that the ecologies of mites, other arachnids and insects are so intimately interconnected.

4. What are 1) the key activities / outputs that the group would undertake / deliver to better understand and address these issues, and 2) how will these activities / outputs contribute to the SSC Strategic Plan?

In essence, MSG members and its five advisory groups (Acarological Society of America, Acarological Society of Japan, Acarological Society of Iran, Latin American Society of Acarology and Saving Nature) are encouraged to contribute to a global effort to conserve mite diversity through research, education, advocacy, collaboration and conservation initiatives by:

1. proposing species for Red List Assessment (RLA) (the MSG has compiled a list of more than 80 species for assessment by its RLA Coordinator, Dr. Agnieszka Napierala)

2. supporting and engaging in taxonomic and ecological studies that contribute to real conservation gains

3. forming direct links with NGOs (e. g. conservation groups, farmer organizations, reforestation societies), indigenous groups, landholders and government agencies to achieve measurable conservation outcomes; to date, the first steps have been taken in developing productive relationships with MarineBio Conservation Society, Saving Nature, the Turkish Foundation for Combating Soil
Erosion and the Wet Tropics Management Authority in Australia

4. supporting and contributing to initiatives that address habitat destruction, climate change, pollution, pesticide use and other drivers of biodiversity loss

5. encouraging the incorporation of mites (and other invertebrates) into the fabric of the biology curriculum in schools and higher education institutions

6. conducting research related to mite conservation issues

7. establishing links with the mass media and a presence in on-line platforms to promote the group and its activities

8. educating/informing government agencies, conservation area managers and the public about the fundamental role that mites and the other invertebrates play in diverse, healthy, productive ecosystems, and

9. engaging in personal behaviors and actions that demonstrate a commitment to the vision of the IUCN, namely, 'a just world that values and conserves nature through positive action to reduce the loss of diversity of life on earth'.

Everyone in the MSG and its advisory groups has been invited to put forward other ideas. The phrase, 'Think globally, act locally' is highly applicable. All MSG members and advisory group members are encouraged to consider how the MSG can be most effective in conserving mite biodiversity at the local, regional and global levels and act on those suggestions while always remembering that any gains for mites are multiplied as gains for other invertebrates, plants and vertebrates.

5. Is there a core group of relevant experts willing to dedicate energy and time towards furthering a conservation agenda for mites?

To date, a group of 65 acarologists and non-acarologists from 36 countries on 5 continents and with a wide range of expertise have joined the group, although large areas in Africa and South-East Asia appear to be lacking in sufficient local acarological expertise. However, some MSG members are personally familiar with and/or have contacts in those areas. Fifty eight persons in the MSG, to a greater or lesser extent, work directly with mites, and a considerable number were members of the Scientific Committee for the XV International Congress of Acarology in Antalya, Turkey in 2018. The other members of the MSG have expertise in botany, ecology, conservation, environmental activism and protected area management that complements the expertise of the mite specialists. The MSG aims to reduce any gaps in its regional coverage as it becomes more established. The group will communicate via email and on social media platforms to disseminate information within and about the group, and formally through the IUCN SSC. Persons interested in joining the MSG should contact the first author, the chair of the group. 


\section{Group leadership}

The MSG's Chair is Sebahat K. Ozman-Sullivan from Ondokuz Mayls University in Turkey. The group's Vice Chairs are Ashley Dowling of the University of Arkansas in the USA and Maria Orlova from Tyumen State University in Russia. The Red List Authority Coordinator is Agnieszka Napierala from the Adam Mickiewicz University in Poland and the Conservation Initiatives Coordinator is Gregory T. Sullivan of The University of Queensland in Australia.

7. Reporting to the Species Survival Commission of the IUCN

Reporting processes revolve around quadrennial targets set by the group in consultation with the SSC (the current period is 2021 - 2024). Targets are allocated to the five components of the Species Conservation Cycle (Assess, Plan, Act, Network and Communicate). The current targets include the identification of both general and specific threats to mites across the wide spectrum of ecosystems they inhabit, raising the profile of mites in terms of greater community understanding of their fundamental importance to global ecological functioning and the provision of ecosystem services, development of partnerships to achieve practical conservation outcomes and the assessment of representative mite species according to the IUCN Red List criteria (IUCN, 2021).

\section{CONCLUSIONS}

The newly formed Mite Specialist Group of the IUCN's Species Survival Commission cannot alone 'save' the mites in a world becoming increasingly degraded by both human population growth and the increasing demand for natural resources that drive habitat destruction, pollution and climate change. However, by boldly and collaboratively pursuing its research, education, advocacy and conservation goals, the group can put mites and their fundamental role in global ecology directly on the international conservation agenda. Moreover, through cooperation with other Species Survival Commission entities, other IUCN commissions, the IUCN secretariat and IUCN member groups, and non-affiliated groups and individuals pursuing similar objectives, the Mite Specialist Group can make a substantial contribution to reducing the overall loss of mite diversity, with any gains for mites multiplied as gains for other invertebrates, vertebrates and plants.

\section{Authors' contributions}

Sebahat K. Ozman-Sullivan: Conceptualization, writing original draft (equal), writing - review \& editing (supporting). Gregory T. Sullivan: Writing - original draft (equal), writing - review \& editing (lead).

\section{Statement of ethics approval}

Not applicable.

Funding

There was no funding received for this study.

\section{Conflict of interest}

The authors declare that they have no conflict of interest regarding this paper.

\section{Acknowledgements}

The authors thank Dr. Axel Hochkirch, Chair of the IUCN SSC Invertebrate Conservation Committee and Co-Chair of the IUCN SSC Grasshopper Specialist Group, Department of Biogeography, Trier University, Germany for numerous helpful comments on the manuscript, and both Dr. Sergio Henriques, Invertebrate Conservation Coordinator at the Global Center for Species Survival, Indianapolis Zoo, and co-chair of the SSC Spider and Scorpion Specialist Group, and Dr. Hochkirch, for sharing their considerable expertise and also their generous personal support during the process of establishment of the Mite Specialist Group of the IUCN's Species Survival Commission.

\section{REFERENCES}

Ceballos, G., Ehrlich, P.R. and Raven, P.H. 2020. Vertebrates on the brink as indicators of biological annihilation and the sixth mass extinction. Proceedings of the National Academy of Sciences of the United States of America, 117 (24): 13596-13602. doi: 10.1073/pnas.1922686117

Conservation International. 2021. Biodiversity hotspots: Targeted investment in nature's most important places. Available https://www.conservation.org/priorities /biodiversity-hotspots (Last accessed: 19 May 2021).

Fonseca, C.R. 2009. The silent mass extinction of insect herbivores in biodiversity hotspots. Conservation Biology, 23 (6): 1507-1515.

doi: 10.1111/j.1523-1739.2009.01327.x

Harvey, J.A., Heinen, R., Armbrecht, I., Basset, Y., BaxterGilbert, J.H. et al. 2020. International scientists formulate a roadmap for insect conservation and recovery. Nature Ecology and Evolution, 4: 174-176. doi: 10.1038/s41559-019-1079-8

Henriques, S., Böhm, M., Collen, B., Luedtke, J., Hoffmann, M. et al. 2020. Accelerating the monitoring of global biodiversity: Revisiting the sampled approach to generating Red List Indices. Conservation Letters, 13 (3): e12703.

doi: 10.1111/conl.12703

Hochkirch, A., Samways, M.J., Gerlach, J., Böhm, M., Williams, P. et al. 2021. A strategy for the next decade to address data deficiency in neglected biodiversity. Conservation Biology, 35 (2): 502-509.

doi: 10.1111/cobi.13589

Hu, X., Huang, B., Verones, F., Cavalett, O. and Cherubini, F. 2021. Overview of recent land-cover changes in biodiversity hotspots. Frontiers in Ecology and the Environment, 19: 91-97. doi: 10.1002/fee.2276 
IUCN, 2021. International Union for Conservation of Nature. Available https://www.iucn.org (Last accessed: 02 July 2021).

Mittermeier, R.A., Robles Gil, P., Hoffman, M., Pilgrim, J., Brooks, T. et al. 2005. Hotspots revisited: Earth's biologically richest and most endangered terrestrial ecoregions. University of Chicago Press, Chicago, USA, $392 \mathrm{pp}$.

Myers, N. 1988. Threatened biotas: "hot spots" in tropical forests. Environmentalist, 8: 187-208.

doi: $10.1007 / B F 02240252$

Myers, N., Mittermeier, R.A., Mittermeier, C.G., da Fonseca, G.A.B. and Kent, J. 2000. Biodiversity hotspots for conservation priorities. Nature, 403: 853-858. doi: 10.1038/35002501

Napierała, A., Książkiewicz-Parulska, Z. and Błoszyk, J. 2018. A Red List of mites from the suborder Uropodina (Acari: Parasitiformes) in Poland. Experimental and Applied Acarology, 75: 467-490. doi: 10.1007/s10493-018-0284-5

Pimm, S.L. 2021. What is biodiversity conservation? Ambio, 50 (5): 976-980.

doi: $10.1007 / s 13280-020-01399-5$

Pimm, S.L., Jenkins, C.N., Abell, R., Brooks, T., Gittleman, J.L. et al. 2014. The biodiversity of species and their rates of extinction, distribution and protection. Science, 344 (6187): 1246752.

doi: 10.1126/science.1246752
Stork, N.E. 2018. How many species of insects and other terrestrial arthropods are there on earth? Annual Review of Entomology, 63: 31-45.

doi: 10.1146/annurev-ento-020117-043348

Strona, G. and Bradshaw, C.J.A. 2018. Co-extinctions annihilate planetary life during extreme environmental change. Scientific reports, 8 (1): 16724. doi: 10.1038/s41598-018-35068-1

Sullivan, G.T. and Ozman-Sullivan, S.K. 2021. Alarming evidence of widespread mite extinctions in the shadows of plant, insect and vertebrate extinctions. Austral Ecology, 46 (1): 163-176. doi: 10.1111/aec.12932

Tixier, M.-S. and Kreiter, S. 2009. Arthropods in biodiversity hotspots: the case of the Phytoseiidae (Acari: Mesostigmata). Biodiversity and Conservation, 18 (3): 507-527. doi: 10.1007/s10531-008-9517-y

Wagner, D.L., Grames, E.M., Forister, M.L., Berenbaum, M.R. and Stopak, D. 2021. Insect decline in the Anthropocene: Death by a thousand cuts. Proceedings of the National Academy of Sciences of the United States of America, 118 (2): e2023989118. doi: $10.1073 /$ pnas.2023989118

Walter, D.E. and Proctor, H.C. 2013. Mites: Ecology, evolution and behaviour: Life at a microscale. Second Edition. Springer, Dordrecht, The Netherlands, 404 pp. doi: 10.1007/978-94-007-7164-2

Edited by: Salih Doğan

Reviewed by: Four anonymous referees

Citation: Ozman-Sullivan, S.K. and Sullivan, G.T. 2021. The newly formed Mite Specialist Group of the IUCN's Species Survival Commission and the conservation of global mite diversity. Acarological Studies, 3 (2): 51-55. 